\title{
Association of Physical Activity and Sitting Time with Overweight/Obesity in Chinese Occupational Populations
}

\author{
Fan Yuan Weiyan Gong Caicui Ding Hui Li Ganyu Feng Yanning Ma \\ Jing Fan Chao Song Ailing Liu
}

Department of Nutrition and Health Education, National Institute for Nutrition and Health Chinese Center for Disease Control and Prevention, Beijing, China

\section{Keywords}

Physical activity $\cdot$ Sitting time $\cdot$ Overweight - Obesity . Occupational populations

\begin{abstract}
Abstract: The aim of this study was to explore association of physical activity and sitting time with overweight/obesity in Chinese occupational populations for the development of intervention and prevention strategies for obesity. Methods: A total of 23,112 participants were selected from the 20102012 China National Nutrition and Health Survey (CNNHS). A logistics regression model was used to examine the associations of physical activity and sitting time with overweight/ obesity by gender after adjusting for age, educational level, marital status, and family economic level. Results: The prevalence of overweight/obesity based on the WHO definition and the WGOC definition was $30.8 \%$ and $41.3 \%$, respectively. Male employees with moderate and heavy occupation activity intensity had a lower risk for overweight/obesity than those with light occupation activity intensity (moderate: OR 0.90, 95\% Cl 0.82-0.98; heavy: OR 0.75, 95\% Cl 0.65-0.86), and the risk of overweight/obesity of male employees with long work-time spent sitting was higher than those with short work-time spent sitting (2-4.9 h/day: OR $1.26,95 \% \mathrm{Cl}$
\end{abstract}

karger@karger.com www.karger.com/ofa

Karger $\stackrel{\text { ' }}{5}$

GOPEN ACCESS
(C) 2021 The Author(s)

Published by S. Karger AG, Basel

This article is licensed under the Creative Commons AttributionNonCommercial-NoDerivatives 4.0 International License (CC BYNC-ND) (http://www.karger.com/Services/OpenAccessLicense). Usage and distribution for commercial purposes as well as any distribution of modified material requires written permission.
1.14-1.40; $\geq 5$ h/day: OR $1.29,95 \%$ Cl 1.15-1.44). The risk of overweight/obesity of male employees with active transportation mode was lower than those with inactive transportation mode (OR 0.91, 95\% Cl 0.84-0.99), while the risk of overweight/obesity of female employees with active transportation mode was higher (OR 1.14, 95\% Cl 1.04-1.25). Female employees with leisure-time physical activity (LTPA) for $\geq 150 \mathrm{~min} /$ week had lower risk of overweight/obesity than those with LTPA for $<150$ min/week (OR 0.69, 95\% Cl 0.560.84). There was no significant association of leisure-time sitting and housework time with overweight/obesity in Chinese occupational populations. Conclusion: Occupation activity intensity, LTPA, transportation mode, and work sitting time were associated with overweight/obesity. Reducing work sitting time, moderate and heavy occupation activity intensity, and an active transportation mode could help male employees decrease the risk of overweight/obesity. Increasing leisure-time physical activity could reduce the risk of overweight/obesity in women. Our findings provided insight into the association of physical activity and sitting time with overweight/obesity. It will be necessary to carry out workplace-based interventions, have an active transportation mode, and increase leisure-time physical activity to decrease the risks of overweight/obesity.

(C) 2021 The Author(s)

Published by S. Karger AG, Basel

Ailing Liu

National Institute for Nutrition and Health Chinese Center for

Disease Control and Prevention, No. 27 Nanwei Road, Xicheng District

Beijing 100050 (China)

liual@ninh.chinacdc.cn 


\section{Introduction}

Overweight/obesity has become a major public health issue. Worldwide obesity nearly tripled from 1975 to 2016. Over 1.9 billion adults ( $\geq 18$ years of age) were overweight in 2016, and $>650$ million of them were obese [1]. According to a national health and nutrition surveillance report in 2016, the prevalence of overweight and obesity among Chinese adults was $30.1 \%$ and $11.9 \%$, respectively [2]. The prevalence of overweight and obesity among occupational populations in Beijing and Shaanxi provinces was $39.0 \%$ and $31.2 \%$, respectively $[3,4]$. The prevalence of overweight and obesity of Dutch workers was $37 \%$ [5]. In Australia, 41.6\% of workers were overweight/obese [6]. Overweight/obesity has become a common health problem, especially in the occupational population [7].

Overweight/obesity is a major risk factor for chronic non-communicable diseases, including diabetes, cardiovascular diseases, musculoskeletal disorders, and some cancers [8-13]. The occupational population is an important pillar of social and economic development, and the health of this group plays an important role in economic development and social stability. Higher calorie intake than energy expenditure is the fundamental cause of obesity and overweight. Previous studies have confirmed that overweight and obesity were associated with lower levels of physical activity $[14,15]$.

Physical activity refers to any bodily movement produced by skeletal muscles that requires energy expenditure, including leisure time, occupational, domestic, and commuting physical activity [16]. Physical activity is closely related to human health. With economic development, great changes have taken place in people's work and lifestyle. The intensity of occupation activity has been significantly reduced by scientific and technological progress, and $>60 \%$ of Chinese occupational populations work with light occupation activity intensity which lead to less physical activity [17]. More and more, private cars, subways, and buses have made transportation more convenient [18]. The widespread availability of entertainment devices such as televisions, computers, and smartphones have increased sedentary behavior [19].

Therefore, it has become necessary to explore the association of physical activity and sitting time with overweight/obesity among current Chinese occupational populations, so as to formulate strategies for intervention and the prevention of obesity.

\section{Materials and Methods}

\section{Study Design}

We obtained data for this study from the China National Nutrition and Health Survey (CNNHS) 2010-2012 [20]. The CNNHS was a nationally representative cross-sectional survey which covered 31 provinces, autonomous regions, and municipalities (except for Taiwan, Hong Kong, and Macao). A design of cluster random sampling with multistage stratification proportional to population size was used to recruit subjects [20,21].

Height and weight measurements were taken by trained medical staff. Sociodemographic information (age, gender, education level, marital status, family income, etc.) and a physical activity questionnaire were collected by trained investigators using faceto-face interviews. The physical activity questionnaire included the topics: work time and intensity, work sitting time, transportation mode, leisure time physical activity (LTPA), housework time, and leisure time sedentary behaviors.

\section{Study Participants}

The total number of CNNHS 2010-2012 participants was 160,480 , which included 87,533 adults aged $18-59.9$ years. A total of 23,112 occupational adults aged 18-59.9 years were included in the study. The occupational adults included unit leaders, professional and technical workers, clerical and related workers, agricultural, forestry, pastoral, fishing and water conservancy production personnel, business and service workers, production and transportation workers, and others. Participants with missing sociodemographic and physical activity data as well as those taking measures to lose weight were excluded.

\section{Definition of Overweight and Obesity}

BMI was calculated using the formula: BMI = weight $(\mathrm{kg}) /$ height $(\mathrm{m})^{2}$. Overweight/obesity was defined as BMI $\geq 24$ based on the criteria of the Working Group on Obesity in China (WGOC) [22]. To increase comparability with other countries, overweight/ obesity was defined as BMI $\geq 25$ according to the World Health Organization (WHO) [1].

\section{Categories of Study Variables}

Demographic Characteristic

Age was grouped as a categorical variable: 18-29, 30-39, 40-49, and $\geq 50$ years. Educational levels were categorized into 4 levels: junior high school or below, senior high school, junior college, Bachelor's or higher. Family economic level was divided into 3 levels: low (less than CNY 20,000), middle (CNY 20,000-40,000), and high (more than CNY 40,000), according to the per capita annual income of urban and rural households in 2011.

Self-Reported Physical Activity during the Past Three Months

Physical activity included 4 domains: occupation activity intensity, transportation mode, housework time, and LTPA.

Occupation Activity Intensity. The participants reported their occupation activity intensity according to their work intensity [23]. Occupation activity intensity was classified as: light, moderate, and heavy.

Transportation Mode. All the participants were asked about their main mode of transportation to/from work, and travel time to/from work every day. Transportation mode was classified as active transportation (walking or cycling), and inactive transporta- 
Table 1. Characteristics of the participants

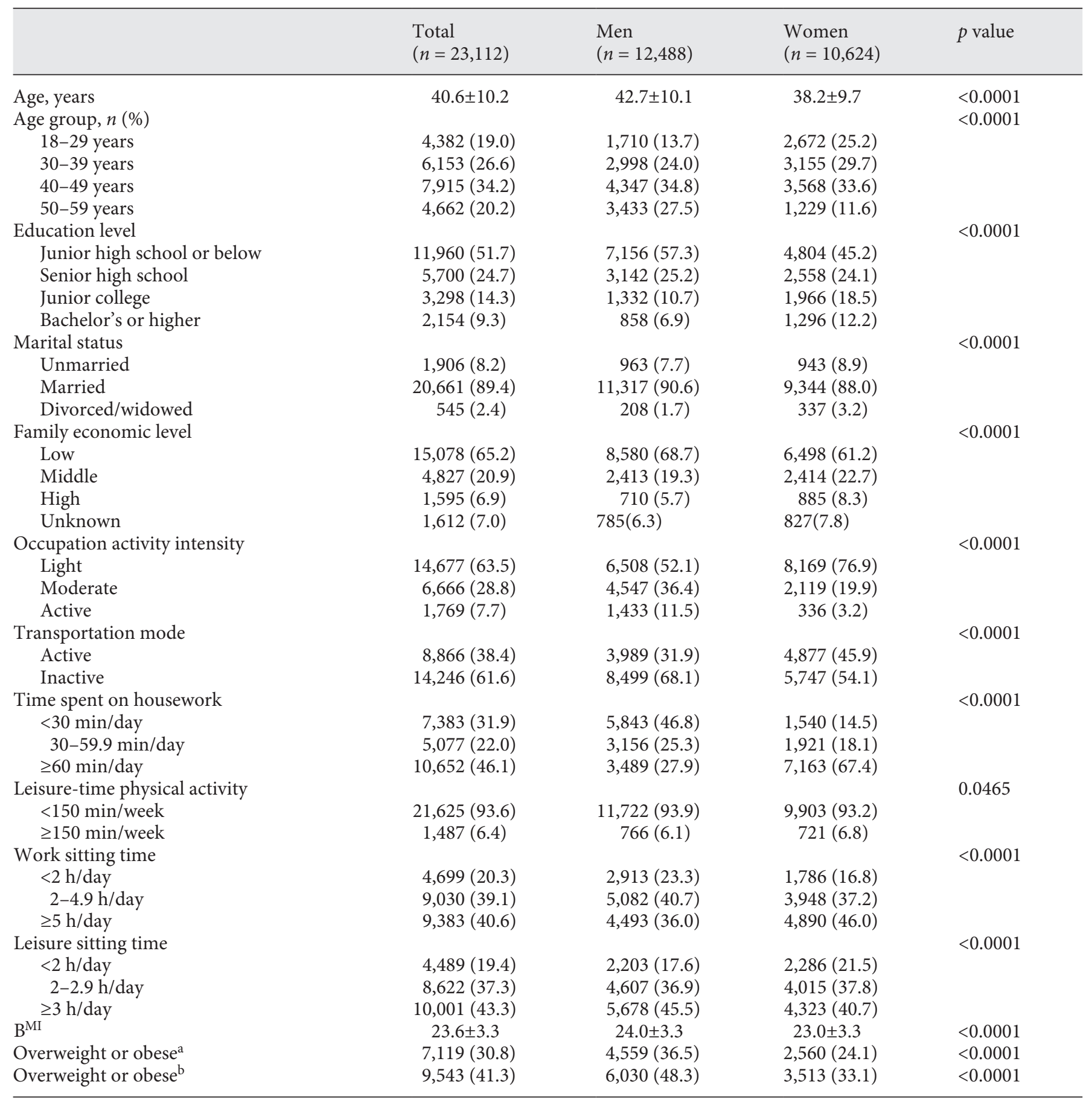

Values are expressed as $n(\%)$ or mean \pm SD. ${ }^{\text {a }}$ Based on the WHO definition; ${ }^{\mathrm{b}}$ based on the WGOC definition.

tion (driving a car or taking a bus, subway, motorcycle, taxi, or electric bicycle) [23].

Housework Time. The participants reported how much time they spent on housework every day. Housework level was categorized as $<30,30-59.9$, or $\geq 60 \mathrm{~min} /$ day.

Physical Activity and Overweight/Obesity
Leisure-Time Physical Activity. The participants were asked the question, "How many days a week do you exercise at a moderate or high intensity? How many hours of exercise a day?". LTPA level was dichotomized as $<150$ or $\geq 150 \mathrm{~min} /$ week [24]. 
Table 2. Logistic regression analysis of the association of physical activity and sitting time with overweight/obesity ${ }^{\mathrm{a}}$ by gender

\begin{tabular}{|c|c|c|c|c|}
\hline & \multicolumn{2}{|l|}{ Men } & \multicolumn{2}{|l|}{ Women } \\
\hline Light & 1.00 & 1.00 & 1.00 & 1.00 \\
\hline Moderate & $0.90(0.83-0.98)$ & $0.90(0.82-0.98)$ & $1.20(1.07-1.35)$ & $1.04(0.93-1.17)$ \\
\hline Active & $0.77(0.67-0.88)$ & $0.75(0.65-0.86)$ & $1.37(1.07-1.75)$ & $1.07(0.83-1.37)$ \\
\hline Active & $0.95(0.87-1.02)$ & $0.91(0.84-0.99)$ & $1.28(1.17-1.40)$ & $1.14(1.04-1.25)$ \\
\hline \multicolumn{5}{|c|}{ Leisure time physical activity } \\
\hline$<150 \mathrm{~min} /$ week & 1.00 & 1.00 & 1.00 & 1.00 \\
\hline$\geq 150 \mathrm{~min} /$ week & $1.02(0.88-1.19)$ & $1.01(0.86-1.18)$ & $0.72(0.60-0.88)$ & $0.69(0.56-0.84)$ \\
\hline \multicolumn{5}{|c|}{ Time spent on housework } \\
\hline$<2 \mathrm{~h} /$ day & 1.00 & 1.00 & 1.00 & 1.00 \\
\hline $2-4.9 \mathrm{~h} /$ day & $1.23(1.11-1.36)$ & $1.26(1.14-1.40)$ & $0.99(0.87-1.13)$ & $1.09(0.96-1.25)$ \\
\hline$\geq 5 \mathrm{~h} /$ day & $1.24(1.11-1.38)$ & $1.29(1.15-1.44)$ & $0.85(0.74-0.97)$ & $1.00(0.87-1.15)$ \\
\hline \multicolumn{5}{|c|}{ Leisure sitting time sitting } \\
\hline$<2 \mathrm{~h} /$ day & 1.00 & 1.00 & 1.00 & 1.00 \\
\hline $2-2.9 \mathrm{~h} /$ day & $1.03(0.93-1.15)$ & $1.04(0.93-1.16)$ & $1.03(0.92-1.16)$ & $1.10(0.97-1.24)$ \\
\hline$\geq 3 \mathrm{~h} /$ day & $1.06(0.95-1.17)$ & $1.09(0.98-1.21)$ & $0.93(0.83-1.05)$ & $1.04(0.92-1.17)$ \\
\hline
\end{tabular}

Bold type denotes significance. OR, odds ratio; CI, confidence interval. ${ }^{a}$ Based on the WHO definition. ${ }^{\mathrm{b}}$ Unadjusted for age, educational level, marital status, and family economic level. ${ }^{c}$ Adjusted for age, educational level, marital status, and family economic level.

Sitting Time

Work Sitting Time. All the participants were asked the questions "How many hours do you work every day, and how many hours do you sit at work?" Work sitting time was classified as 3 levels: $<2,2-4.9$, or $\geq 5 \mathrm{~h} /$ day.

Leisure Sitting Time. All the participants reported the time they spent sitting during leisure time. The question asked was "How many hours do you sit in leisure time every day, such as watching $\mathrm{TV}$, using a computer, reading, and so on?" Leisure sitting time was classified as $<2,2-2.9$, or $\geq 3 \mathrm{~h}$ /day.

\section{Statistical Analyses}

Data analyses were conducted using SAS software v9.4 (SAS Institute, Cary, NC, USA). The $\chi^{2}$ test was performed for comparing demographic characteristics, physical activity, and the prevalence of overweight/obesity between different genders. A logistics regression model was used to examine the association of physical activity and sedentary behaviors with overweight/obesity by gender, where the dependent variable was BMI status (normal weight $=0$, overweight and obesity $=1$ ). Independent variables included 4 domains of physical activity and 2 indicators of sitting time, with or without adjustments for age, educational level, marital status, and family economic level. $p=0.05$ was considered statistically significant.

\section{Results}

Characteristics of Participants

Table 1 presents the basic characteristics of the participants. The mean age was 40.6 years. The prevalence of overweight/obesity based on the WHO definition and the WGOC definition was $30.8 \%$ and $41.3 \%$, respectively. The prevalence of overweight/obesity in men was higher than that in women $(p<0.01)$. There were also significant differences in age, education level, marital status, family economic level, occupation activity intensity, transportation mode, LTPA, housework time, work sitting time, and leisure sitting time between the genders $(p<0.05)$.

\section{Associations of Physical Activity and Sitting Time with Overweight/Obesity by Gender}

Table 2 shows the associations of physical activity and sitting time with overweight/obesity by gender. After adjusting for age, educational level, marital status, and family economic level, male employees with moderate occu- 
pation activity intensity (OR $0.90,95 \%$ CI $0.82-0.98$ ) and heavy occupation activity intensity (OR 0.75 , 95\% CI $0.65-0.86$ ) had a significantly lower risk of overweight/ obesity compared to those with light occupation activity intensity. Men spending 2-4.9 h/day (OR 1.26, 95\% CI $1.14-1.40$ ) and $>5$ h/day (OR $1.29,95 \%$ CI $1.15-1.44$ ) of their work-time sitting had a higher risk of overweight/ obesity than those sitting for $<2 \mathrm{~h} /$ day. The risk of overweight/obesity of male employees with an active transportation mode was lower than those with inactive transportation mode (OR 0.91, 95\% CI 0.84-0.99), while the risk of overweight/obesity of female employees with an active transportation mode was higher (OR 1.14, 95\% CI 1.04-1.25). Women with LTPA for $\geq 150 \mathrm{~min} /$ week had lower risk of overweight/obesity (OR 0.69, 95\% CI 0.560.84 ) than those with LTPA for $<150 \mathrm{~min} /$ week.

\section{Discussion}

Our study showed that male employees with moderate and heavy occupation activity intensity had a lower risk of overweight/obesity, and the risk of overweight/obesity of male employees with a long work-time spent sitting was higher than those who spent a short time sitting at work. The risk of overweight/obesity of male employees with active transportation mode was lower than those with inactive transportation mode, while the risk of overweight/ obesity of female employees with an active transportation mode was higher. Female employees with LTPA for $\geq 150$ $\mathrm{min} /$ week had lower risk of overweight/obesity.

Most studies have confirmed that moderate to heavy occupation activity intensity could reduce the risk of overweight and obesity [25-27]. A previous study confirmed that occupation activity accounted for $62 \%$ of total physical activity [28]. Occupation activity has been a key determinant of weight gain [29]. Our study found that moderate and heavy occupation activity intensity were significantly associated with a lower risk of overweight/ obesity in male employees but not in females, consistent with the result obtained by Xu et al. [23]. This may be due to the fact that most women engaged in light occupation activity intensity. With the advancement of technology, light occupation activity intensity is dominant in many high-income countries and also in some developing countries, including China [17]. The lack of physical activity in the workplace is becoming an important factor in the development of overweight and obesity. Therefore, we suggest that women and men engage in light occupation activity intensity should increase their LTPA.

Physical Activity and Overweight/Obesity
The study also showed that LTPA for $\geq 150 \mathrm{~min} /$ week had a lower risk of overweight/obesity in female employees but not in males, the result was not consistent with the findings of Xu et al. [23]. A study in Canada found that LTPA was inversely associated with obesity in men and with both overweight and obesity in women [30]. Chinese dietary guidelines recommend at least $150 \mathrm{~min}$ of moderate-tohigh intensity LTPA a week. This study confirmed that $\geq 150$ min of moderate or high-intensity LTPA per week could reduce the risk of overweight and obesity in females.

Active transportation promotes energy expenditure [31]. Transportation mode can also influence obesity [32, 33]. We found overweight/obesity was associated with transportation mode. Active transportation decreased the risk of overweight/obesity in men but not in women. According to the research of Gong et al. [18], female travel time was shorter than that of males. This may be due to insufficient walking/cycling intensity or distances, i.e., not enough to prevent obesity.

Sitting time is considered an independent risk factor for overweight and obesity $[34,35]$. Work sitting time and leisure sitting time are two important components of sitting time. Work sitting time had been found to be associated with overweight/obesity in men [24]. Our study also showed long work sitting time was associated with a higher risk of overweight/obesity in men but not in women. Long leisure sitting time was a risk factor for overweight/obesity in another study [35], but our study did reveal this association. The possible explanation could be that leisure sitting time contributed less to overall sitting time than work sitting time.

Although several previous studies had reported an inverse association between housework and obesity [36, 37], results from the British Women's Heart and Health Study showed that heavy housework was not associated with reduced levels of being overweight [38]. Our study did not find the association of housework time with overweight/obesity. Perhaps as technology has progressed, the use of electric stoves, washing machines, dishwashers, and vacuum cleaners has led people to expend less energy while doing housework [39].

Our study showed the prevalence of overweight/obesity among the occupational population of $41.3 \%$ (based on the WGOC definition) in 2012. Compared with 2002, the prevalence of overweight/obesity among Chinese occupational groups thus increased by $13.1 \%$ [7]. Increasing overweight and obesity have now become a major public health issue in the occupational population. There is a need for policy-makers to pay attention to the overweight and obesity in Chinese occupational populations and to develop relevant intervention strategies. 
Our research is important for the development of these strategies. The major strength of our study was that the sample was nationally representative, so the results reflect the association of physical activity domains and sedentary behaviors with overweight/obesity in Chinese occupational populations. There were some limitations, however. First, physical activity and sedentary behaviors were self-reported, which can lead to recall bias. Second, this study did not adjust for the effects of energy intake on overweight/obesity.

Occupation activity intensity, LTPA, transportation mode, and work sitting time were found to be associated with overweight/obesity. Reducing work sitting time, a moderate and heavy occupation activity intensity, and an active transportation mode could help male employees decrease the risk of overweight/obesity. Increasing LTPA could decrease the risk of overweight/obesity in women. It is very necessary to carry out workplace-based interventions, have an active transportation mode, and increase LTPA to decrease the risks of overweight/obesity.

\section{Acknowledgement}

We would like to thank all the participants who took part in this study and the staff from the 31 provinces involved in the 20102012 CNNHS.

\section{Statement of Ethics}

Written informed consent was obtained from each participant. The protocol was approved by the Ethics Committee of the $\mathrm{Na}$ tional Institute for Nutrition and Health Chinese Center for Disease Control and Prevention (No. 2013-010).

\section{Conflict of Interest Statement}

The authors have no conflicts of interest to declare.

\section{Funding Sources}

The survey in 2010-2012 was funded by a major program for health care reform run by the National Health and Family Planning Commission of the People's Republic of China (No. 20120212).

\section{Author Contributions}

F.Y. wrote the manuscript and researched data. W.G., C.D., H.L., G.F., Y.M., J.F., C.S., and A.L. researched data, oversaw data collection and analysis, contributed to writing of the manuscript, and reviewed and edited the manuscript. All authors were involved in writing of the paper and had final approval of the submitted and published versions.

\section{References}

1 WHO. [Internet] Obesity and overweight [cited April 1, 2020]. Available from: https:// www.who.int/news-room/fact-sheets/detail/ obesity-and-overweight.

2 Chang JL, Wang Y. Surveillance Report on Nutrition and Health Status of Chinese Residents (2010-2013)-Comprehensive Report. Beijing, China: Peking University Medical Press; 2016.

3 Zhao FH, Li YH, Liu M, Tao MX, Wan GF. Prevalence of overweight/obesity and its relevant influencing factors among occupational populations in Beijing. Chin J Health Educ. 2014;30:12-7.

4 Cao XX, Wang MQ, Fang XZ. Epidemic characters of overweight obesity and center obesity among 4 professional populations in Shaanxi Province. Chin J Health Educ. 2017; 33:608-11.

5 Proper KI, Hildebrandt VH. Overweight and obesity among Dutch workers: differences between occupational groups and sectors. Int Arch Occup Environ Health. 2010 Jan;83(1): 61-8.

6 Chau JY, van der Ploeg HP, Merom D, Chey T, Bauman AE. Cross-sectional associations between occupational and leisure-time sit- ting, physical activity and obesity in working adults. Prev Med. 2012 Mar-Apr;54(3-4): 195-200.

7 Ma GS, Luan DC, Liu AL, Li YP, Cui ZH, Hu $\mathrm{XQ}$. The relation between physical activity level and overweight-obesity among Chinese professionals. Ying Yang Xue Bao. 2007;29: 426-30.

8 Robertson J, Lindgren M, Schaufelberger M, Adiels M, Björck L, Lundberg CE, et al. Body Mass Index in Young Women and Risk of Cardiomyopathy: A Long-Term Follow-Up Study in Sweden. Circulation. 2020 Feb; 141(7):520-9.

9 Kearns K, Dee A, Fitzgerald AP, Doherty E, Perry IJ. Chronic disease burden associated with overweight and obesity in Ireland: the effects of a small BMI reduction at population level. BMC Public Health. 2014 Feb;14(1): 143.

10 Jafar TH, Chaturvedi N, Pappas G. Prevalence of overweight and obesity and their association with hypertension and diabetes mellitus in an Indo-Asian population. CMAJ. 2006 Oct; 175(9): 1071-7.

11 Wilson PW, D'Agostino RB, Sullivan L, Parise H, Kannel WB. Overweight and obe- sity as determinants of cardiovascular risk: the Framingham experience. Arch Intern Med. 2002 Sep;162(16):1867-72.

12 Brown CD, Higgins M, Donato KA, Rohde FC, Garrison R, Obarzanek E, et al. Body mass index and the prevalence of hypertension and dyslipidemia. Obes Res. 2000 Dec;8(9):60519.

13 Lamon-Fava S, Wilson PW, Schaefer EJ. Impact of body mass index on coronary heart disease risk factors in men and women. The Framingham Offspring Study. Arterioscler Thromb Vasc Biol. 1996 Dec;16(12):150915.

14 Martínez-González MA, Martínez JA, Hu FB, Gibney MJ, Kearney J. Physical inactivity, sedentary lifestyle and obesity in the European Union. Int J Obes Relat Metab Disord. 1999 Nov;23(11):1192-201.

15 Zhang X, Sun Z, Zhang X, Zheng L, Liu S, Xu $\mathrm{C}$, et al. Prevalence and associated factors of overweight and obesity in a Chinese rural population. Obesity (Silver Spring). 2008 Jan; 16(1):168-71.

16 WHO. Physical activity. [cited April 1, 2020]. Available from: https://www.who.int/newsroom/fact-sheets/detail/physical-activity. 
17 Yuan F, Chen Z, Zhang Y, Feng GY, Gong WY, Ding CC, et al. Status of physical activity among occupational populations in China: a cross-sectional study. Chin J Publ Health. 2018;34:1327-30.

18 Gong W, Yuan F, Feng G, Ma Y, Zhang Y, Ding C, et al. Trends in Transportation Modes and Time among Chinese Population from 2002 to 2012. Int J Environ Res Public Health. 2020 Feb;17(3):E945.

19 Guo H, Ding C, Yuan F, Zhang Y, Chen Z, Liu A. Sedentary behavior during leisure time and social determinants among Chinese adults in 2010-2012. Wei Sheng Yan Jiu. 2017 Sep; 46(5):699-704. Chinese.

20 Ding C, Song C, Yuan F, Zhang Y, Feng G, Chen Z, et al. The Physical Activity Patterns among Rural Chinese Adults: Data from China National Nutrition and Health Survey in 2010-2012. Int J Environ Res Public Health. 2018 May;15(5):E941.

$21 \mathrm{Hu}$ Y, Chen J, Wang R, Li M, Yun C, Li W, et al. Vitamin D Nutritional Status and Its Related Factors for Chinese Children and Adolescents in 2010-2012. Nutrients. 2017 Sep; 9(9):E1024.

22 Chen C, Lu FC; Department of Disease Control Ministry of Health, PR China. The guidelines for prevention and control of overweight and obesity in Chinese adults. Biomed Environ Sci. 2004;17(suppl):1-36.

$23 \mathrm{Xu}$ CX, Zhu HH, Fang L, Hu RY, Wang H, Liang $\mathrm{MB}$, et al. Gender disparity in the associations of overweight/obesity with occupational activity, transport to/from work, leisure-time physical activity, and leisure-time spent sitting in working adults: A cross-sectional study. J Epidemiol. 2017 Sep;27(9): 401-7.
24 Mummery WK, Schofield GM, Steele R, Eakin EG, Brown WJ. Occupational sitting time and overweight and obesity in Australian workers. Am J Prev Med. 2005 Aug;29(2):917.

25 King GA, Fitzhugh EC, Bassett DR Jr McLaughlin JE, Strath SJ, Swartz AM, et al. Relationship of leisure-time physical activity and occupational activity to the prevalence of obesity. Int J Obes Relat Metab Disord. 2001 May;25(5):606-12.

26 Monda KL, Adair LS, Zhai F, Popkin BM. Longitudinal relationships between occupational and domestic physical activity patterns and body weight in China. Eur J Clin Nutr. 2008 Nov;62(11):1318-25.

27 Steeves JA, Bassett DR Jr, Thompson DL, Fitzhugh EC. Relationships of occupational and non-occupational physical activity to abdominal obesity. Int J Obes. 2012 Jan;36(1): 100-6.

28 Du H, Li L, Whitlock G, Bennett D, Guo Y, Bian Z, et al.; China Kadoorie Biobank Collaborative Group. Patterns and socio-demographic correlates of domain-specific physical activities and their associations with adiposity in the China Kadoorie Biobank study. BMC Public Health. 2014 Aug;14(1):826.

29 Bell AC, Ge K, Popkin BM. Weight gain and its predictors in Chinese adults. Int J Obes Relat Metab Disord. 2001 Jul;25(7):1079-86.

30 Chen Y, Mao Y. Obesity and leisure time physical activity among Canadians. Prev Med. 2006 Apr;42(4):261-5

31 Audrey S, Procter S, Cooper AR. The contribution of walking to work to adult physical activity levels: a cross sectional study. Int J Behav Nutr Phys Act. 2014 Mar;11(1): 37.
32 Lindström M. Means of transportation to work and overweight and obesity: a population-based study in southern Sweden. Prev Med. 2008 Jan;46(1):22-8.

33 Wen LM, Rissel C. Inverse associations between cycling to work, public transport, and overweight and obesity: findings from a population-based study in Australia. Prev Med. 2008 Jan;46(1):29-32.

34 Bauman A, Allman-Farinelli M, Huxley R, James WP. Leisure-time physical activity alone may not be a sufficient public health approach to prevent obesity-a focus on China. Obes Rev. 2008 Mar;9(suppl 1):119-26.

35 Bullock VE, Griffiths P, Sherar LB, Clemes SA. Sitting time and obesity in a sample of adults from Europe and the USA. Ann Hum Biol. 2017 May;44(3):230-6.

$36 \mathrm{Chu}$ AH, Moy FM. Associations of occupational, transportation, household and leisuretime physical activity patterns with metabolic risk factors among middle-aged adults in a middle-income country. Prev Med. 2013; 57(suppl):S14-7.

37 Banks E, Lim L, Seubsman SA, Bain C, Sleigh A. Relationship of obesity to physical activity, domestic activities, and sedentary behaviours: cross-sectional findings from a national cohort of over 70,000 Thai adults. BMC Public Health. 2011 Oct;11(1):762

38 Lawlor DA, Taylor M, Bedford C, Ebrahim S Is housework good for health? Levels of physical activity and factors associated with activity in elderly women. Results from the British Women's Heart and Health Study. J Epidemiol Community Health. 2002 Jun;56(6): 473-8.

39 Lanningham-Foster L, Nysse LJ, Levine JA. Labor saved, calories lost: the energetic impact of domestic labor-saving devices. Obes Res. 2003 Oct;11(10):1178-81. 